\title{
Preceptors' perceptions of supporting nursing students in Prison Health Services: A qualitative study
}

\begin{abstract}
Background: Our University commenced clinical placements for third-year nursing students in Prison Health Services (PHS) in 2014. Registered nurse preceptors employed in these services facilitated students' experiential workplace learning, assessed their competence and assisted them to meet course objectives in this challenging environment. To date no studies have examined preceptors' experiences of supporting students in the prison health setting. Aim: The study aim was to investigate preceptors' perceptions of supporting nursing students undertaking clinical placements in PHS, in order to inform development of resources and processes.
\end{abstract}

Methods: Qualitative data were collected via a focus group and interviews with preceptors $(\mathrm{n}=6)$ working in metropolitan PHS. Data underwent thematic analysis.

Findings: Participants valued the opportunity to support student learning, finding students contributed to the workplace by bringing in new ideas, and conducting beneficial projects. However, preceptors requested better rostering and workload management by their employer. They also wished for more detailed information from the university regarding student orientation and preparation to support student learning. They felt that the employer-provided preceptorship training did not fulfil their needs.

Discussion: Preceptors in PHS settings shared many of the support needs of those in other settings, although some challenges were more specific to the setting.

Conclusion: This paper makes recommendations on how preceptors in PHS can be better supported to fulfil the role. 
Keywords: preceptor, nursing student, prison health, nursing

\section{Summary of relevance}

\section{Problem}

Registered nurse preceptors facilitate students' experiential workplace learning in the challenging prison health services (PHS) setting, however their support needs and experiences have not been examined.

\section{What is already known}

No research has previously been conducted on the experiences of nurse preceptors in the PHS setting.

\section{What this study adds}

Barriers to effective preceptorship in the PHS setting included lack of useful training and feedback for preceptors, lack of preceptor continuity, and lack of an effective orientation for students. Nurse preceptors working in PHS sought more support to fulfil their role. 


\section{INTRODUCTION}

In Australia, nursing student numbers have increased in response to the predicted shortfall of Registered Nurses (RNs) related to an ageing and increasingly part-time nursing workforce, poor nurse retention rates, and population health trends across the ageing population (Health Workforce Australia (HWA), 2014a). The increased numbers of nursing students have led to a substantial increase in demand on clinical placements (HWA, 2014a).

Nursing roles have also diversified with changes to Australian healthcare. Nurses are providing more community and primary healthcare, and increasingly working in health promotion and prevention, health education and management, administration, and policy (HWA, 2013). This, combined with difficulty sourcing sufficient quality nursing student placements in traditional sectors, prompted one Australian University to begin placing thirdyear nursing students in Prison Health Services (PHS). This PHS provided primary care to inmates of correctional facilities, which in this study were secure facilities in which persons who have been convicted of a crime were detained to serve their sentence. This study explored the experiences of RNs who engaged with the nursing students as preceptors during PHS placements to identify their views on the barriers to, and enablers of supporting students in this setting, and how they engaged students in learning in order to inform development of helpful resources and processes.

\section{BACKGROUND}

The Australian Nursing and Midwifery Accreditation Council (ANMAC) (2012) mandates that Bachelor of Nursing programs provide at least 800 hours of workplace experience that allows undergraduate students to develop their professional nursing attributes 
in authentic settings under guidance from clinicians on the procedures and expectations of the clinical environment.

Various titles are used internationally to describe RNs who have some role in facilitating nursing students' learning on clinical placement including clinical facilitators, preceptors, mentors, and buddy nurses, among others (Needham et al., 2016; Rebeiro et al., 2017; Ward \& McComb, 2017). According to Rebeiro et al. (2015), a clinical facilitator is formally trained and appointed and can be employed either by the education provider or the health service to support student learning on clinical placement. Clinical facilitators typically supervise a number of students concurrently. Preceptors are clinical supervisors who have a temporary one to one supervisory relationship with a student (Rebiero et al., 2015). Buddy nurses have a more informal relationship with their supervisees and are generally not involved in student assessment (Rebeiro et al., 2015). Mentor is another title used in some countries to describe nurses who support nursing students to achieve their goals on placement (Oikarainen et al., 2018). The title familiar to participants in this study was preceptors.

Preceptors in this study were RNs who worked with nursing students to develop their learning in the clinical setting. The preceptor role was undertaken in addition to the nurse's usual workload (HWA, 2014b). It included orientating students, providing access to relevant resources and guidance, skill development support, coaching, and counselling (HWA, 2014b). Preceptors require skills in conflict resolution, providing appropriate feedback, and mentoring, and should scan the clinical setting for contextual learning opportunities (Henderson \& Eaton, 2013; Shinners \& Franqueiro, 2015).

Preceptors in this study were RNs who at a minimum had been registered for more than two years and had at least two years clinical experience in this area. In some instances, the preceptors had worked in PHS since their graduation. The state Health Department at the time of this study offered preceptor programs and the opportunity to complete certificates in 
training and assessment via vocational education training organisations. Preceptors were encouraged to undertake professional development within the higher education sector in the areas of adult education and learning.

A literature search was conducted using the PubMed, CINAHL and MEDLINE databases to investigate the research related to precepting students in prison health settings. Search terms used included undergraduate nurse clinical placement/ practicum/ offender/ prisoner/correctional/jail/gaol health, preceptor/mentor, and clinical supervision. While multiple studies have been published on preceptors' experiences across a range of other healthcare settings, no research detailing the experiences and needs of preceptors in PHS was found.

Prison Health Services are considered suitable sites for undergraduate student learning (Bouchaud \& Swan, 2017; van de Mortel et al., 2017), but the experiences of preceptors and the support they require in this setting have not been investigated. This study aimed to rectify this gap in the context of the Australian PHS setting. The research questions were:

1. What do preceptors see as the barriers or enablers to supporting nursing student learning in PHS?

2. How do preceptors in PHS engage students in learning?

\section{METHODS}

\section{Design and participants}

A qualitative descriptive methodology was used. Qualitative research does not seek to generalise but rather to develop understanding of the phenomena (Polit \& Beck, 2010). Nurse preceptors $(n=20)$ working with our students in an Australian metropolitan PHS during 2015 were invited to participate via an email invitation from the research assistant, that included an 
information sheet and consent form. The PHS provided primary care to adult male and adult female correctional centres, and a youth detention centre. Participants were offered the choice of a focus group or individual interview to maximise the flexibility for participants in order to maximise participation. According to Lambert and Loiselle (2008) the combination of both focus groups and interviews is a form of triangulation that can produce a more comprehensive understanding of the issue under investigation.

An interview schedule containing open-ended questions was used to elicit information about preceptor experiences, the types of strategies used to enhance student learning in PHS, and barriers to, and enablers of supporting student learning. The same questions were used for the focus group and individual interviews. Interviews and focus groups were conducted and recorded by a research assistant who was not part of the PHS workforce. The focus group duration was 50 minutes, and the individual interviews ranged from 22 to 43 minutes in duration.

\section{Ethics approval}

Ethics approval was obtained from the Hospital and Health Service (HREC/15/QMWS/38) and University (Ref No: NRS/47/15/HREC) Human Research Ethics Committees. The research conformed to the "Statement on Human Experimentation" by the National Health and Medical Research Council of Australia. Written informed consent was obtained from participants. Codes were used to protect participant confidentiality and enable tracking of data. Data were stored in password protected files and locked cabinets.

\section{Data analysis}


Interview recordings were transcribed by a commercial transcribing service. A multiphase thematic analysis of the transcripts was conducted using inductive qualitative techniques (Clarke \& Braun, 2013; Nowell et al., 2017). Steps included were immersion in these data through multiple reads through transcripts, coding the information, collating codes into themes, naming themes, and selecting illustrative quotes that exemplify these (Clarke \& Braun, 2013).

Guba and Lincoln (1989) describe several key processes to ensure trustworthiness in qualitative research. In this study the credibility of the findings was tested through inclusion in the team of an expert PHS nurse educator. We also provided representative quotes to allow readers to infer how the findings could be transferred to other contexts. We ensured dependability and credibility through using consistent processes to record and interpret data, for example, using the same questions in the same sequence, providing a decision-making trail, and using a process of review to ensure objectivity in the analysis. In our study two researchers independently read and reviewed the transcripts, and recurrent phrases were summarised then collated, grouped, and sorted. Themes emerged across and between transcripts, with final decisions on themes based on full agreement among the researchers.

\section{RESULTS}

Of the 20 eligible preceptors, six participated: four via a focus group, and two via individual interview.

\section{Themes}


Four key themes emerged from these data: Adequacy of Preparation (subthemes: Preceptor Preparation, Student Preparation), Contextual Factors (subthemes: Challenging Environment, Challenging Client Population, Management Issues), Personal Characteristics and Engagement (subthemes: Students' Attitudes, Engagement, and Skills; Staff Engagement), and Student Learning (Providing Learning Opportunities that Meet Needs, Preceptor Self-Reflection, Techniques to Support Learning, Placement Duration). These are described below with illustrative quotes.

\section{Adequacy of preparation}

\section{Preceptor preparation}

Lack of adequate preceptor training was seen as a barrier to supporting nursing students. Two participants had no formal training, three had completed an industry preceptor workshop, and one a Workplace Training and Assessment Certificate. Most felt they could be better prepared for the precepting role, and comments about the standard training provided by the health department included, "it wasn't anything that I didn't already know. I left thinking, well I didn't get anything out of that, so what am I supposed to be doing... what is my role?" [P6]. Participants emphasised a lack of sufficient guidance, requesting more information on "what [the students] need to get out of it and what they need to achieve" [P1]. Preceptors felt ‘no-one supports us, we just support ourselves” [P2].

Participants desired more role clarity, asking "What are we supposed to be doing? Are we covering it? How do they feel about it?" [P6], and also citing a lack of feedback on their own performance as an issue, "I believe [the students] do give feedback...I thought, was I different with these? It's hard to know because ... it's ad hoc; we're not following a structure. Is it just because it's at the end of the year and I got better at it, or were they more receptive” [P6]? Preceptors asked for "structures" [P2], "learning frameworks” [P3], and 
"guidelines" [P6], and for a more comprehensive format for obtaining student information prior to placement than what the university provided, stating "If we had a better format, that'd decrease my cranky levels...there's so many [international] students...I don't know if that's a male or female name. I can tell Tammy and Edward and some like that, but the rest is like, 'We'll have to wait and see what we get this time"' [P1].

\section{Student preparation}

Participants felt students were sometimes underprepared for PHS, stating "sometimes they come expecting what we do to be totally different" [P2], and "I don't think the students...get any correctional information. They don't tend to know a lot about...the population" [P3].

Participants indicated the need for better student preparation in relation to safety, the facility, the client population and typical health conditions and medications, for example, 'information about the facility... the types of medications... involved in psych, analgesia, things like that which is certainly relevant to adult prisons" [P3], "environmental safety" [P1], and for the youth detention centre, "child safety stuff" [P1]. Safety issues that should be included in orientation included security procedures, for example, "you can't go anywhere without an escort, you have to be with somebody at all times...you can't bring phones, even to go to the loo [toilet] at our place, it's a locked door and they have to ask one of us...they need to bring their own meals in...they've got to bring their stuff in in plastic bags...there can't be any sharps" [P1], and "what to do in the event of a hostage situation" [P3].

\section{Contextual factors}




\section{Challenging environment}

Prisons are challenging workplaces. The physical environment is " $a$ very controlled environment, a door doesn't open unless someone opens it...some areas can get quite noisy... and it can be a little bit...intimidating" [P5], unlike anything students are likely to have encountered. Students commonly were anxious, but preceptors emphasised, "it's a safe environment, it's not a place that they should be afraid of" [P5], although students needed to be "watching their backs at the same time" [P4], and there are times "when I get a hostile prison or situation you can't involve them in' [P3]. In adult facilities, time was an issue, for example, "you have a student walk in their first day at 6 am, and you've... got 400 people's charts to flip through in two hours...It's overwhelming for a normal person" [P4].

\section{Challenging client population}

The client population are very different as a group to what students are likely to have experienced elsewhere, for example, they exhibit 'different behaviours, you're not dealing with normal people sitting...compliant in a hospital bed" [P6], and "a lot of ours are coming in with ice [methamphetamine addiction]'[P4]. Staff may need to change the way they approach certain situations. For example, preceptors indicated "sometimes you have to change what you might normally do...particularly in prison settings...you may have an abusive person or something, well we don't have to deal with them. It's quite simple. You don't have to worry about what you're going to do, you don't do anything. So, you know, this setting's a little bit different"' [P6].

In youth detention, “[while] they might be here for adult crimes...they're still children, so you have to have that way of talking to a child... you might have gloves and your sterile field, but it goes out the window if they start poking their fingers in it" [P6]. The clients' frequent drug abuse backgrounds introduced new challenges, for example, “you go to 
give them the immunisation in the arm, they throw a big hissy fit, 'Not there. I'll give it to myself,' or they say they want it somewhere else. 'I'll find a vein for you, Miss.' 'I don't need a vein, it's going up in your upper arm"' [P1]. In youth detention in particular, participants felt students sometimes struggled to maintain professional boundaries, stating, "it's amazing how many want to take the kids home or rescue them" [P2]. Participants also identified challenges for students related to client culture, and development. For example, in youth detention " $67 \%$ [are] indigenous, and 70\% of them are intellectually impaired" [P1]; and "They're 11 and they've got ADHD, so you can't talk to them the way you'd talk to a 50-year-old lady...you have to be creative sometimes" [P6].

\section{Management issues}

Some challenges encountered supporting student learning related to management of the facility including workload, staffing, and rostering. Participants indicated, "it's not one person to one student" [P1], "they could be with me one day... could see five other people, so there's not much continuity there...sometimes it has just been the workload-we've just got to get this done... are they more in the way?...Sometimes [due to staff shortages] they're with inexperienced people" [P6], and "They try and allocate their students to one primary responsible person, but with the changes in shifts and absenteeism, it makes it very hard"' [P4].

\section{Personal characteristics and engagement}

\section{Students' attitudes, engagement, and skills}

Preceptors identified that students' engagement, attitudes, confidence and English language skills could impact preceptor workload and engagement in student learning. 
Preceptors found most students to be helpful, although "some are more willing than others" [P6], and 'some were a joy' [P1]. Those that were willing and motivated were seen as easier to support. While the majority of nursing students were described as very engaged, participants stated:

"attitude is a huge thing... it's hard to change...You'll know within a day whether they're going to sit back and just be on the computer all the time...or are they going to be engaged doing stuff? ... it's about their own nature" [P1],

"I've found a lot want to stand back, because they don't have the confidence"[P2],

"we had one who wasn't going to continue nursing when he finished so he was just doing the time" [P4], and

"she just refused to do anything” [P2].

Non-English speaking background can also have an impact, for example, "they've got to translate from written English to Australian English when they're still struggling with their own English" [P1]. Preceptors indicated 'students that don't take any initiative or they sit back and do the minimum and you have to continually prompt and prompt and prompt them to show that initiative' [P4], and 'when you're busy you give up wanting to engage them ... they become really hard work' [P1].

\section{Staff engagement}

Engagement of staff in the preceptor role varied. Not all were keen to support students, for example, some stated, "I know a lot of other nurses who think [precepting] 
interferes with their work" [P5], and "the attitudes of some of the nursing staff could be improved as well....they'll just be hostile. 'No. I don't want a student." [P3]. On the other hand, preceptors saw benefits to themselves and their workplace that motivated them to engage in the precepting role. For example, students "[keep] us all up-skilled and interested" [P1], and "having these people asking you questions makes you think, so it's good for my own practice...I often learn myself" [P5]. Students contributed to the work, brought in new ideas, and conducted beneficial projects, for example, “[during an] influenza outbreak... we pulled out how to line map the infection... without those students I'd have gone and shot myself I think! They were brilliant, because they were line tracing all, who got what first, and filling in my forms for me, and we were doing the whole process" [P1]. Participants also felt that there was an incentive to precepting nursing students as workforce recruitment benefited, stating, "it's building our own... the end result is you have somebody that you're happy to work with as a registered nurse in the future" [P1], and "two of the students from this year are coming on next year as new grads' [P3].

\section{Student learning}

\section{Providing learning opportunities that meet needs}

Preceptors were keen to ensure that the students' learning needs and university expectations were met, indicating, "It's making sure they've got things to do that meet their learning needs, that they get to experience activities that will develop them; that you give them the benefit of expertise and knowledge in different things. It's expanding their knowledge in that field...[making] sure that they're safe" [P], and "making sure how they 
were performing, experiences they were having [were] work appropriate for the subject and the year and those expectations" [P3].

Preceptors attempted to provide students with a wide range of learning opportunities to meet their learning needs and expand their knowledge of primary care and prison nursing. They recognised that preceptors should adapt to the student's age, level of understanding and experience, stating, "[some] are obviously used to engaging with patients... another person who is quite young... may come across as not quite as confident - we go back to basics” [P5]. Opportunities related to "the emergent thing of what's happening at the time" were used to stimulate learning, clinical reasoning and reflective practice, including projects, and case studies. For example, students were opportunistically involved in mapping an infectious disease outbreak (described above), or developing a training package, for example, ' $m y$ two students... are working on a training package for the nursing staff on their responsibilities on the management of [developmental disabilities]' [P1].

Preceptors saw PHS as providing opportunities to develop students' skills and knowledge about "working as partners on the multidisciplinary team" [P2], as the nurses worked closely with community services and the mental health team. Other opportunities included developing students' skills in medication administration, assessment and 'primary care" [P4] for example, “a hearing clinic... asthma education ... pill run" [P2], "mental health assessments" [P2], and communication skills, "they can talk to the prisoners and be comfortable with that" [P3].

\section{Preceptor self-reflection}

Preceptors' reflections on their own student experience enabled them to provide a better experience for students, for example, "when I was a student on my second last prac I had a really hard time and I try not to do that" [P5]. Student discomfort in the learning 
process was also described as being a constructive tool, for example, "I know I didn't like that as a student myself, because it does tend to put you on the spot a little bit, but in hindsight ... that was the stuff I really remembered" [P5].

\section{Techniques to support learning}

Preceptors used a range of techniques to support student learning including demonstration and role modelling, starting from and building upon the basics, questioning to develop reflection and decision-making skills, and providing encouragement and feedback.

Preceptors felt it important that students observe their practice, then practice under supervision stating, “...you come and watch me do this...next time you do the same thing and I'll be with you" [P6], and "I like to show them how I do things and then I get them to gradually get in and do it themselves, so by the time they leave they can do everything themselves, under supervision" [P4]. It was also "really important to show a very good example of how to conduct yourself...they take good traits of that and mirror" [P3], and "it's about modelling the professional behaviours too, watching your professional boundaries" [P1].

Working from simple concepts to the more complex was important to build student confidence. Preceptors stated, "Let's go back to basics...I generally find over that ... by the end of four weeks there's no problem” [P6], 'you start small' [P1], and "I say, 'Okay, well you just go slowly and at your own pace' and eventually they can actually do a whole file themselves...by the time they leave, they can do it, it's good" [P3].

Preceptors used questioning to support student learning, for example, "I try to get them to explain what they're thinking; what they're doing at any given time. I ask them, 'Why? What are you doing? Why are you doing that?" [P5] and "What are you thinking we should $d o ?$ ?[P3] Students were encouraged to make use of prison resources such as charts, policies 
and manuals. Chart reviews and case studies were used to stimulate learning and clinical reasoning to, "go through it and pick it to pieces and ask, 'What would you do? ... and get them to think more of their scope” [P3]. Struggling students were encouraged to "... research some policies or guidelines... and rectify the problem" [P5].

Preceptors also encouraged students to reflect on situations to improve their learning, for example, 'then we might just go through it and reflect on it a bit... in order to get them to understand what they did or what just happened" [P5]. Encouragement and positive or timely feedback were also seen as important, for example, "the positive reinforcement goes a long way. Just encouraging them, the positive feedback" [P6], and "if [they're] doing something wrong or are lacking knowledge, then they need to be made aware of that within a reasonable timeframe so that they can catch up" [P5].

\section{Placement duration}

Students do two or four week placements in PHS depending on which course the placement is associated with. Preceptors found the longer placements to be an enabler of student learning, indicating, "[when doing a two week placement] they just start to get used to it. It's a shell shock to come to a prison in the first place, so by the time they've got used to it and they're not being scared anymore, it's time to go. By the time they've been there for a month, they're actually part of the team" [P4].

\section{DISCUSSION}

This study, which explored registered nurses' experiences of precepting nursing students in PHS, is the first of its kind. The results highlight several barriers to, and enablers 
of, preceptorship in PHS, which provide a basis for recommendations to improve preceptor support in this setting.

Barriers to preceptorship in PHS included role ambiguity related to insufficient preceptor training, insufficient student preparation, student characteristics, and challenges related to the prison environment, health service management and the client population. Preceptor role ambiguity has been noted across multiple countries and settings (Omansky, 2010), and preceptors commonly feel poorly supported (L'Ecuyer et al., 2018). CourtneyPratt, Ford and Marlow (2015) suggest that preceptor education is integral to student supervision, however, Carrigan (2012) suggests preceptors may lack teaching experience and educational qualifications, and indeed the majority of our participants either had no formal preceptor education or had attended training they described as sub-optimal. Broadbent et al. (2014) suggests industry preceptorship education lacks sufficient focus on the teaching and assessment of undergraduates. A comprehensive preceptor training package, such as is provided in some other settings, may provide preceptors with a greater understanding of university expectations and encourage networking with academic staff for support (Broadbent et al., 2014).

Participants felt that students were underprepared for the prison placements with respect to the environment, safety, the needs of prisoners and the challenging behaviours they may exhibit. While mental health and community settings have individual clients and/or environments that in some aspects are similar to PHS, the PHS setting is unique in that it comprises populations in which all members are serving a sentence for criminal convictions in a secure facility with very rigid security requirements that exceed those required for secure mental health units; the highly socially disadvantaged population also has a high frequency of mental health issues and/or intellectual disabilities, drug and alcohol addictions, and chronic co-morbidities (Australian Institute of Health and Welfare, 2015). The perceived lack of 
preparation is concerning as poor preparation diminishes students' performance on placement (Scanlan \& Chernomas, 2016). While most preceptors stressed the safety of the environment, they noted that aspects may be challenging for undergraduate students including safety issues, and the impact of the prison security culture on care delivery. Nursing students attending PHS placements have also remarked on the stresses associated with the client population, the perceived safety threats, the - at times - confronting work environment and interpersonal interactions and the need for a specific PHS orientation (van de Mortel et al., 2017).

Preceptors found that some students lacked initiative and motivation, which impacted adversely on engagement with learning opportunities, preceptor workload and work satisfaction. These issues are not just associated with the correctional setting (Scanlan \& Chernomas, 2016), and may be in part addressed through better student preparation.

Participants in this study desired better workload and rostering management to allow them to fulfil their role and maintain preceptor continuity. This is a common finding in the literature across multiple countries and settings (Jansson \& Ene, 2016; Rebeiro et al., 2015), and students on PHS placements have also commented on the lack of preceptor continuity (van de Mortel et al., 2017). Students should be rostered to work with their nominated preceptor as frequently as possible, or with an appropriate alternative preceptor when this is not possible (Sundler et al., 2014) as discontinuity is a potential stressor (Jansson \& Ene, 2016).

In addition to better preceptor training and student orientation, other enablers included clearer guidelines and information on students' learning needs and student support processes, a more comprehensive format for presentation of pre-placement student information and more feedback on their own performance. Preceptor guidelines have been recognised as important in other specialty placement areas to improve learning outcomes (Coyne \& 
Needham, 2012). Given the university provides a printed guide for clinical facilitators and preceptors, better communication with preceptors regarding available resources is clearly required. Requests for more information on student and university needs and formal channels to assist preceptors dealing with student issues are also common in other settings (Broadbent et al., 2014; Scanlan \& Chernomas, 2016; Ward \& McComb, 2017).

Given performance feedback was a concern for PHS preceptors, the data the university provides from formal anonymous student evaluations of preceptor performance to preceptors does not appear to be sufficient to their needs. Other mechanisms of providing feedback on performance need to be examined, including peer review. Performance feedback has also been noted to be limited in other settings (Courtney-Pratt et al., 2015).

Finally, participants described positive student attitudes, the possibility of graduate recruitment to the workforce, and the benefits students brought to the clinical area as enablers, as the benefits that accrued to preceptors and the workplace acted as motivators to sustain a commitment to student support. Preceptors described the placements as good for their own and their colleagues' practice, knowledge and professional development, as students brought in new ideas, conducted beneficial projects, and contributed to the work. Similar benefits have been reported in relation to prison (Fraser Hale et al., 2008) and acute care placements (Morrison and Brennaman, 2016).

Despite the different setting, preceptors in PHS used a similar toolbox to those that work in other settings, for example, reflecting on their own experiences as a learner, questioning, demonstration followed by practice under supervision, providing encouragement and timely feedback to build confidence and address performance issues early, and building on prior learning by working from simple to more complex concepts (Henderson \& Eaton, 2013; Shinners \& Franqueiro, 2015; Ward \& McComb, 2017). Students who have attended a PHS placement refer positively to strategies such as encouragement, questioning, practicing 
under supervision, and receiving feedback (van de Mortel et al., 2017). Preceptors also mentioned the importance of role modelling professional boundaries and behaviour towards prisoners as another important aspect of PHS preceptorship, as students may be unsure of how to conduct themselves in interactions with prisoners, which is confirmed by students undergoing PHS placements (van de Mortel et al., 2017).

This small study was conducted with preceptors in an Australian metropolitan PHS. The qualitative nature of these data limit the inferences that can be made related to participants' location, age, culture, and gender, and the ability to generalise findings. While the sample was small, Braun and Clarke (2013), who have written extensively on thematic analysis as a method, suggest that a sample of 5-15 is adequate for a small qualitative study, and indicate that 'bigger isn't necessarily better. The bigger the sample, the greater the risk of failing to do justice to the complexity and nuance contained within the data' (Braun and Clarke, 2016).

\section{CONCLUSIONS}

Preceptors within PHS faced many of the same challenges as those in other healthcare settings and used the same kinds of strategies to support student learning. However, there are also specific challenges as preceptors support undergraduate nursing students' learning in an environment in which all clients have been convicted of a crime; these relate to facilitating student learning in a secure facility, with a very large client population with challenging backgrounds of social disadvantage, intellectual disability, chronic illness and drug and alcohol addiction. Preceptors in this study identified various enablers to support their precepting role. These included further education for PHS preceptors by the university on their role; more detailed performance feedback; rostering by their employer to ensure better continuity with their student's roster, and a more comprehensive student orientation to the 
setting. Future research should investigate the outcome of implementing these recommendations in the PHS setting.

Acknowledgements

This study was funded by a Queensland Clinical Education \& Training Council grant.

Conflicts

Nil 


\section{References}

Australian Institute of Health and Welfare. (2015). The health of Australia's prisoners 2015 [Online]. Retrieved from:

http://www.aihw.gov.au/WorkArea/DownloadAsset.aspx?id.60129553682.

Australian Nursing and Midwifery Accreditation Council. (2012). Registered Nurse Accreditation Standards. Canberra, Australia: Australian Nursing and Midwifery Accreditation Council.

Bouchaud, M. T., \& Swan, B. A. (2017). Integrating Correctional and Community Health Care: An Innovative Approach for Clinical Learning in a Baccalaureate Nursing Program. Nursing Forum, 52, 38-49.

Broadbent, M., Moxham, L., Sander, T., Walker, S., \& Dwyer, T., 2014. Supporting Bachelor of Nursing students within the clinical environment: perspectives of preceptors. Nurse Education in Practice, 14, 403-9.

Braun, V., \& Clarke, V. (2013). Successful qualitative research: A practical guide for beginners. London, UK: Sage.

Braun, V., \& Clarke, V. (2016). (Mis)conceptualising themes, thematic analysis, and other problems with Fugard and Potts' (2015) sample-size tool for thematic analysis. International Journal of Social Research Methodology, 19, 739-743.

Carrigan, C. (2012.) A clinical issue: Training our future nurses. Australian Nursing Journal, $20,22-25$.

Clarke, V., \& Braun, V. (2013). Teaching thematic analysis: over-coming challenges and developing strategies for effective learning. The Psychologist, 26, 120-23.

Courtney-Pratt, H., Ford, K., \& Marlow, A. (2015). Evaluating, understanding and improving the quality of clinical placements for undergraduate nurses: A practice development approach. Nurse Education in Practice, 15, 512-6. 
Coyne, E., \& Needham, J. (2012). Undergraduate nursing student placement in specialty areas: Understanding the concerns of the student and registered nurse. Contemporary Nurse, 42, 97-104.

Fraser Hale, J., Brewer, A. M., \& Ferguson, W. (2008). Correctional Health Primary Care: Research and Educational Opportunities. Journal of Correctional Health Care, 14, 278-289.

Guba, E. G., \& Lincoln, Y. S. (1989). Fourth generation evaluation. Newbury Park, CA: Sage Publications.

Health Workforce Australia. 2013. Australia's Health Workforce Series - Nurses in Focus [Online]. Adelaide, South Australia: Health Workforce Australia. Retrieved from: http://pandora.nla.gov.au/pan/133228/201504190017/www.hwa.gov.au/sites/default/files/Nurses-in-Focus-FINAL.pdf [Accessed 03 February, 2017].

Health Workforce Australia. (2014a). Australia's Future Health Workforce - Nurses Overview.

Health Workforce Australia. (2014b). National Clinical Supervision Competency Resource. Adelaide, Australia: Health Workforce Australia.

Henderson, A., \& Eaton, E. (2013). Assisting nurses to facilitate student and new graduate learning in practice settings: what 'support' do nurses at the bedside need? Nurse Education in Practice, 13, 197-201.

Jansson, I., \& Ene, K. W. (2016). Nursing students' evaluation of quality indicators during learning in clinical practice. Nurse Education in Practice, 20, 17-22.

Lambert, S., \& Loiselle, C. (2008). Combining individual interviews and focus groups to enhance data richness. Journal of Advanced Nursing, 62, 228-237. 
L'Ecuyer, K, Hyde, M., Shatto, B. (2018). Preceptors' perception of role competency. The Journal of Continuing Education in Nursing, 49, 233-240.

Morrison, T. L., \& Brennaman, L. (2016). What do nursing students contribute to clinical practice? The perceptions of working nurses. Applied Nursing Research, 32, 30-35.

Needham, J., McMurray, A., \& Shaban, R. (2016). Best practice in clinical facilitation of undergraduate nursing students. Nurse Education in Practice, 20, 131-138.

Nowell, L., Norris, J., White, D., \& Moules, N. (2017). Thematic analysis: Striving to meet the trustworthiness criteria. International Journal of Qualitative Methods, 16, 1-13.

Oikarainen, A., Mikkonen, K., Tuomiskoski, A, Elo, S., Pitkanen, S., Ruotsalainen, H., \& Kääriäinen, M. (2018). Mentors' competence in mentoring culturally and linguistically diverse nursing students during clinical placement. Journal of Advanced Nursing, 74, 148-159.

Omansky, G. (2010). Staff nurses experiences as preceptors and mentors: An integrative review. Journal of Nursing Management. 18, 697-703.

Polit, D., \& Beck, C. (2010). Generalization in quantitative and qualitative research: myths and strategies. International Journal of Nursing Studies, 47, 1451-8.

Rebeiro, G., Edward, K. L., Chapman, R., \& Evans, A. (2015). Interpersonal relationships between registered nurses and student nurses in the clinical setting - A systematic integrative review. Nurse Education Today, 35, 1206-11.

Rebeiro, G., Evans, A., Edward, K. L., \& Chapman, R. (2017). Registered nurse buddies: Educators by proxy? Nurse Education Today, 55, 1-4.

Scanlan, J. M., \& Chernomas, W. M. (2016). Failing Clinical Practice \& the Unsafe Student: A New Perspective. International Journal of Nursing Education and Scholarship,13.

Shinners, J., \& Franqueiro, T. (2015). Preceptor skills and characteristics: Considerations for preceptor education. Journal of Continuing Nurse Education, 46(5), 233-236. 
Sundler, A. J., Bjork, M., Bisholt, B., Ohlsson, U., Engstrom, A. K., \& Gustafsson, M. (2014). Student nurses' experiences of the clinical learning environment in relation to the organization of supervision: a questionnaire survey. Nurse Education Today, 34, $661-6$.

van de Mortel, T. F., Needham, J., Barnewall, K., Djachenko, A., \& Patrick, J. (2017).

Student nurses' perceptions of clinical placements in Australian Prison Health Services: A mixed methods study. Nurse Education in Practice, 24, 55-61.

Ward, A., \& McComb, S. (2017). Precepting: A literature review. Journal of Professional Nursing, 33, 314-325. 